\title{
Neonatal Epileptic Seizure, AE
}

National Cancer Institute

\section{Source}

National Cancer Institute. Neonatal Epileptic Seizure, AE. NCI Thesaurus. Code C154934.

An adverse event in a newborn characterized by an electroencephalogram (EEG)

confirmed paroxysmal surge of electrical activity in the brain that may result in physical or behavioral changes. 